Dialectologia 17 (2016), 71-89.

ISSN: 2013-2247

Received 7 February 2016.

Accepted 18 April 2016.

\title{
A CENTURY OF LANGUAGE CHANGE IN PROGRESS. NEW DIALECT IN TSURUOKA, JAPAN
}

\author{
Fumio INOUE \\ Tokyo University of Foreign Studies* \\ innowayf@nifty.com
}

\begin{abstract}
In this paper an original research technique developed in Japan will be introduced, and patterns and speed of geographical diffusion will be discussed on the basis of the glottogram technique. Distinction between standardization and new dialect forms will be discussed on the basis of survey results. Contour lines can be utilized to represent linguistic differences between urban and rural areas.
\end{abstract}

\section{Keywords}

new dialect, standardization, diffusion speed, apparent time, glottogram

\section{UN SIGLO DE CAMBIO LINGÜÍSTICO EN PROCESO. \\ UN DIALECTO NUEVO EN TSURUOKA, JAPAN}

\section{Resumen}

En este artículo se presenta una técnica original de investigación desarrollada en Japón, y se discuten los patrones y velocidad de difusión geográfica sobre la base de la técnica del glotograma. Se debate también la distinción entre estandarización y nuevas formas dialectales a partir de los resultados de la encuesta. Las líneas de contorno pueden utilizarse para representar las diferencias lingüísticas entre las zonas urbanas y rurales.

\section{Palabras clave}

nuevo dialecto, estandarización, velocidad de la difusión, tiempo aparente, glotograma

\footnotetext{
* 3-11-1 Asahicho, Fuchu, Tokyo, Japan 183-8534.
} 


\section{Shonai Glottogram}

The main scenes (or stages) of this paper are in the Tsuruoka area in northern Japan. Figure 1 is a map around Tsuruoka city. The original glottogram technique was first applied in this area in Inoue (1975). The lines in the map on the right-hand side indicate the localities investigated, which are situated along a main road from south to north. The large, red arrow shows the area which will be re-analyzed in this paper. The area is shown again on the larger satellite map on the left-hand side. The blue balloon shows the site of Tsuruoka Castle (the old city center). Red circles in Tsuruoka city area show the hypothetical contour lines in and around a local city which will be discussed in section 6.2.

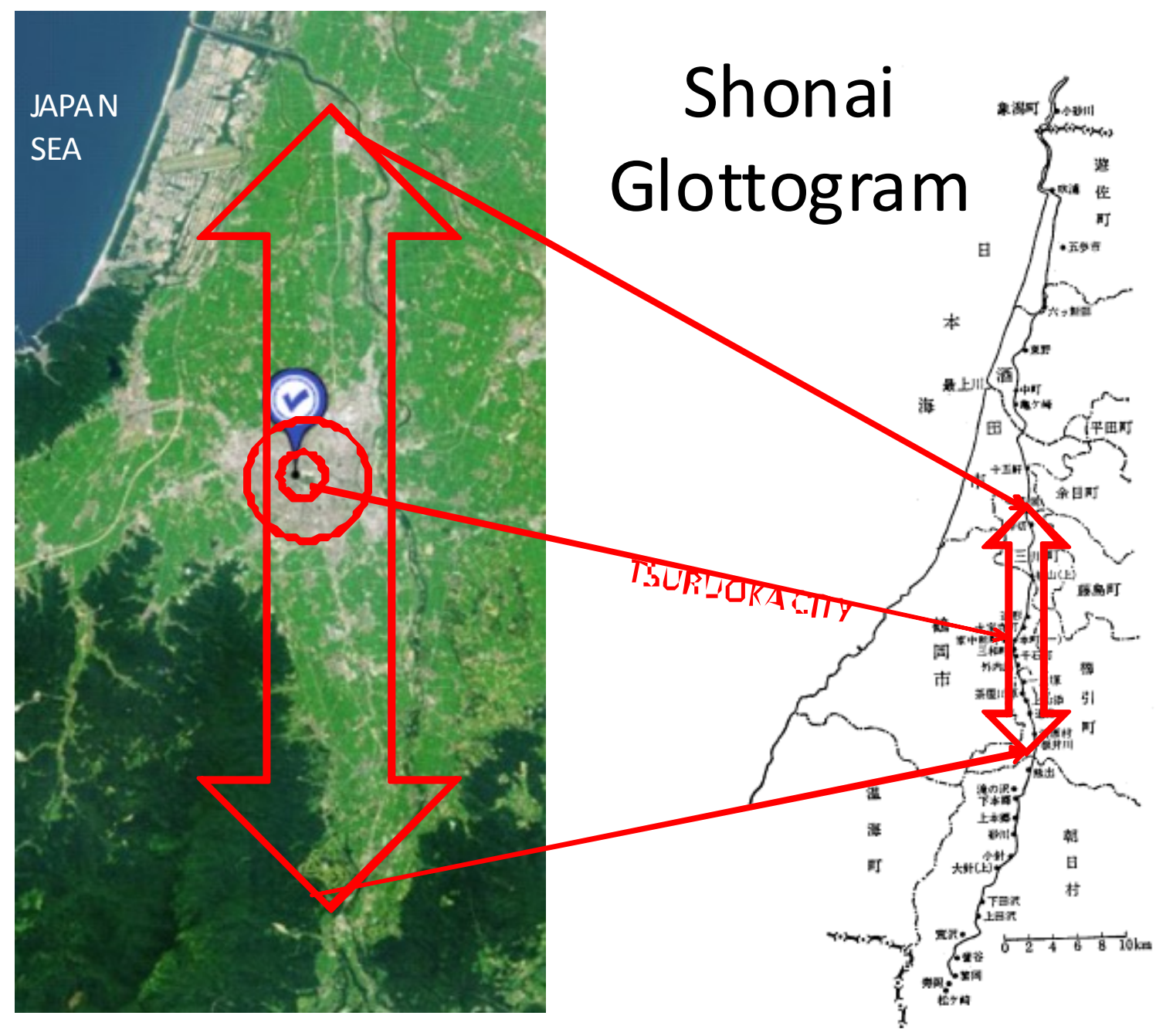

Figure 1. Localities surveyed in Tsuruoka area. 


\section{The Data and Methodology}

\subsection{Original Shonai Glottogram}

Figure 2 is a sample of the original glottogram. A glottogram can be also called an "age area graph". The localities from south to north are horizontally arranged from left to right in Figure 2. Informants are arranged vertically according to age groups. Young people (teens, born around 1960) are shown below and elderly people (in their eighties, born before 1900) are shown above. The glottogram shows the apparent time differences for a time span of sixty to seventy years (Labov 1972).

The red square shows the area which will be re-analyzed in this paper. Fifteen localities are selected for re-analysis this time. These have been selected because they are situated within $12 \mathrm{~km}$ south and north of the Tsuruoka city area (the localities with red letters), and are dialectally under Tsuruoka's influence. The locality with the red K, the former samurai residential area, is postulated as the cultural center of the whole area. Localities with orange letters are suburban, and localities with green letters are rural.

The word shown in this glottogram is 'to give' or kureru in standard Japanese. As the purpose of this glottogram research was mainly to understand the dialect distribution patterns, standard kureru is shown by small dots. Dialectal form is a shortened form, keru. As this dialectal form is noteworthy for its increasing use by young informants, it is shown by impressive large squares, as new dialect forms.

However this glottogram is misleading in the sense that it does not faithfully show geographical distances of localities, nor the age differences of individual informants. 


\section{Shonai Glottogram (kureru > keru)}

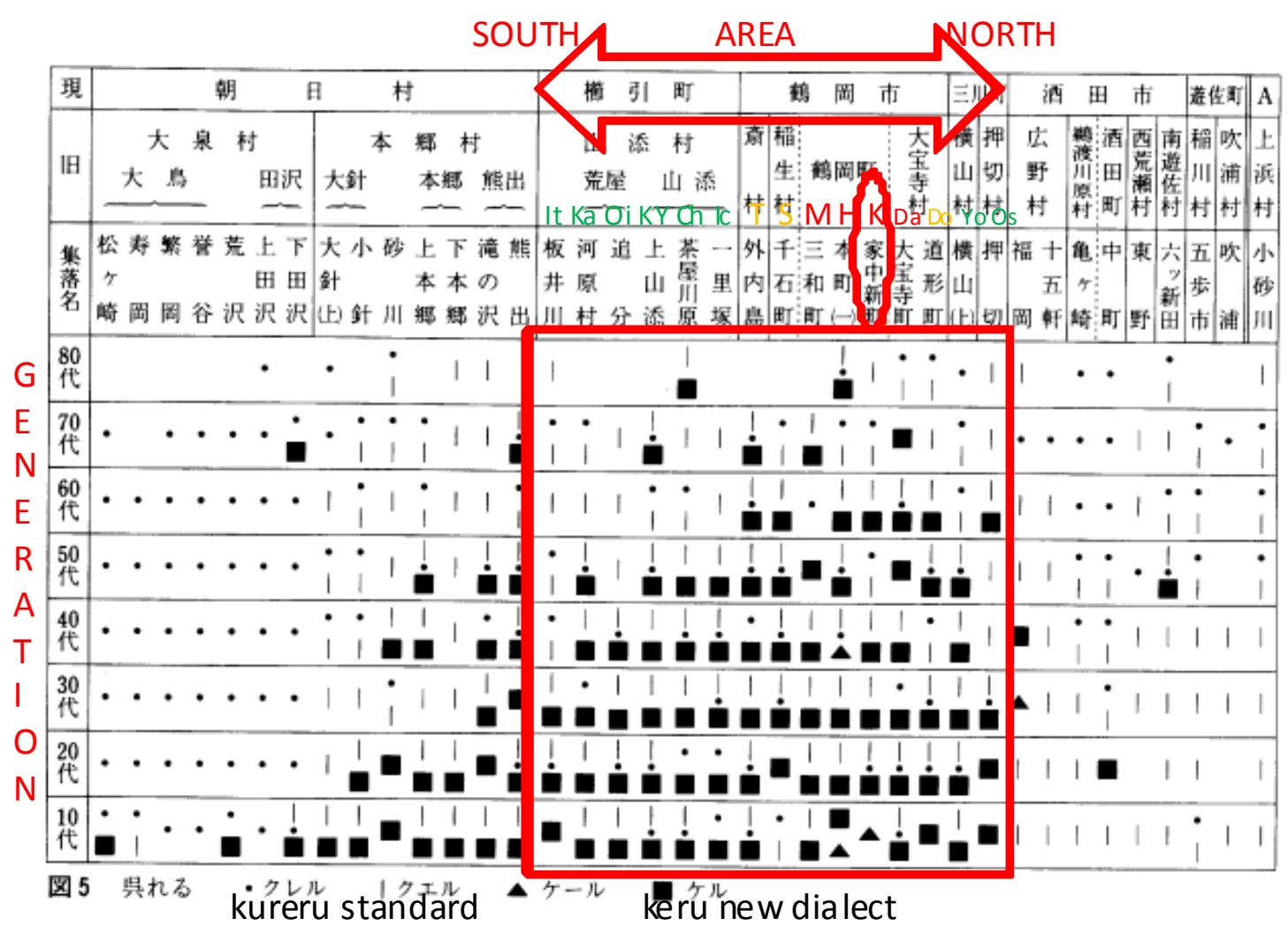

Figure 2. Original Shonai Glottogram.

\subsection{Newer glottogram}

In order to make a new glottogram, the "scattergram" function of EXCEL was utilized. By calculating (1) the distances of the localities from a starting point in the south and (2) the exact birth year of each informant, more faithful glottograms were drawn.

Figure 3 is a sample of a new glottogram for the standard Japanese form, kureru, 'to give'. Here, "2" means that only the standard form kureru is used. "1" means that the standard form is used together with the dialectal form, keru. The red, orange and green letters below show the names of the survey localities. The red ones are urban localities in the old city area of Tsuruoka. The orange are suburban rural (and industrial) localities which were consolidated in Tsuruoka City in the 20th century. The green letters show rural areas. Standard Japanese is used more in the city area. 


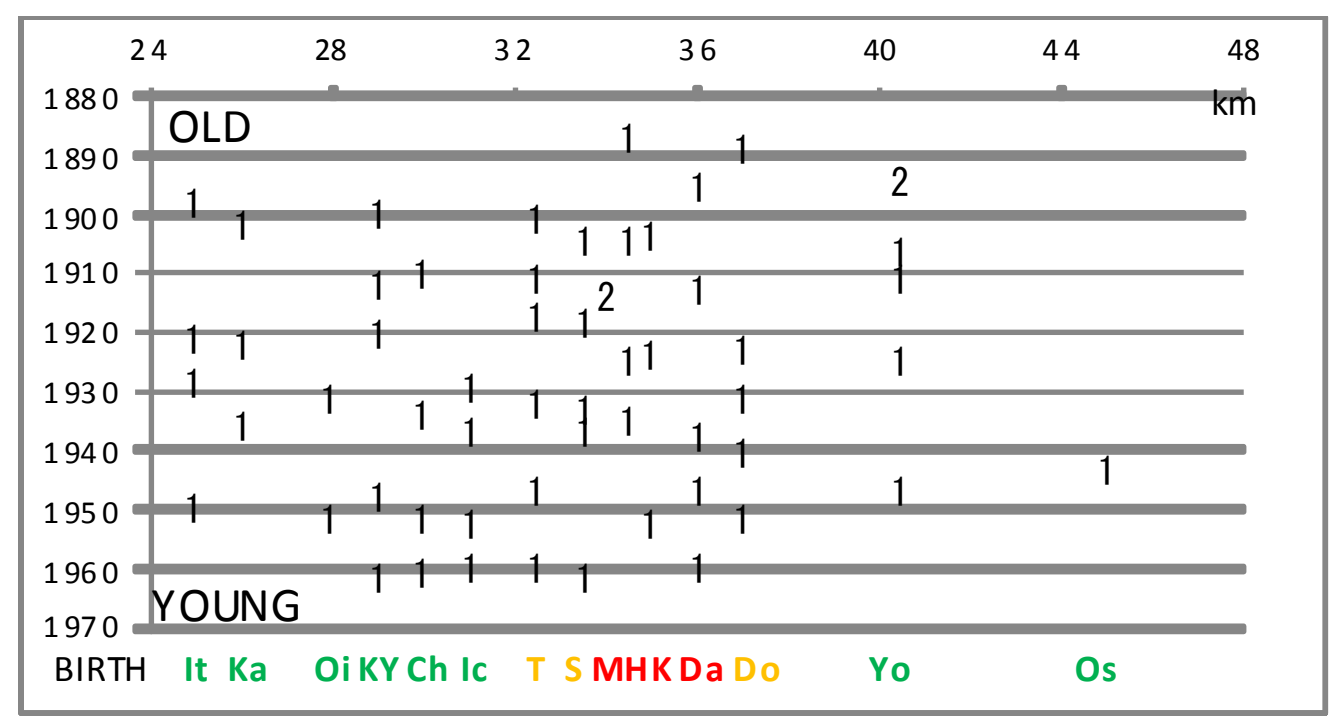

TSURUOKA

Figure 3. Glottogram of Standard Japanese Kureru.

Many more glottograms were drawn and they showed similar distribution patterns. Standard forms are used mainly by younger speakers near the city area.

\subsection{Standardization in Shonai glottogram}

In order to determine the general distribution pattern, the standard Japanese forms of 20 words have been re-analyzed as aggregate data. The total sum of usage of standard forms is shown by symbols in Figure 4. As expected, young speakers in the Tsuruoka city area use more standard forms than the other speakers. The blue line approximations show the general tendency. They resemble three gently-sloping mountains. The communication gap between the urban and suburban rural areas of Tsuruoka does not seem so great when compared with a new dialect form, which will be shown in Figure 6. 


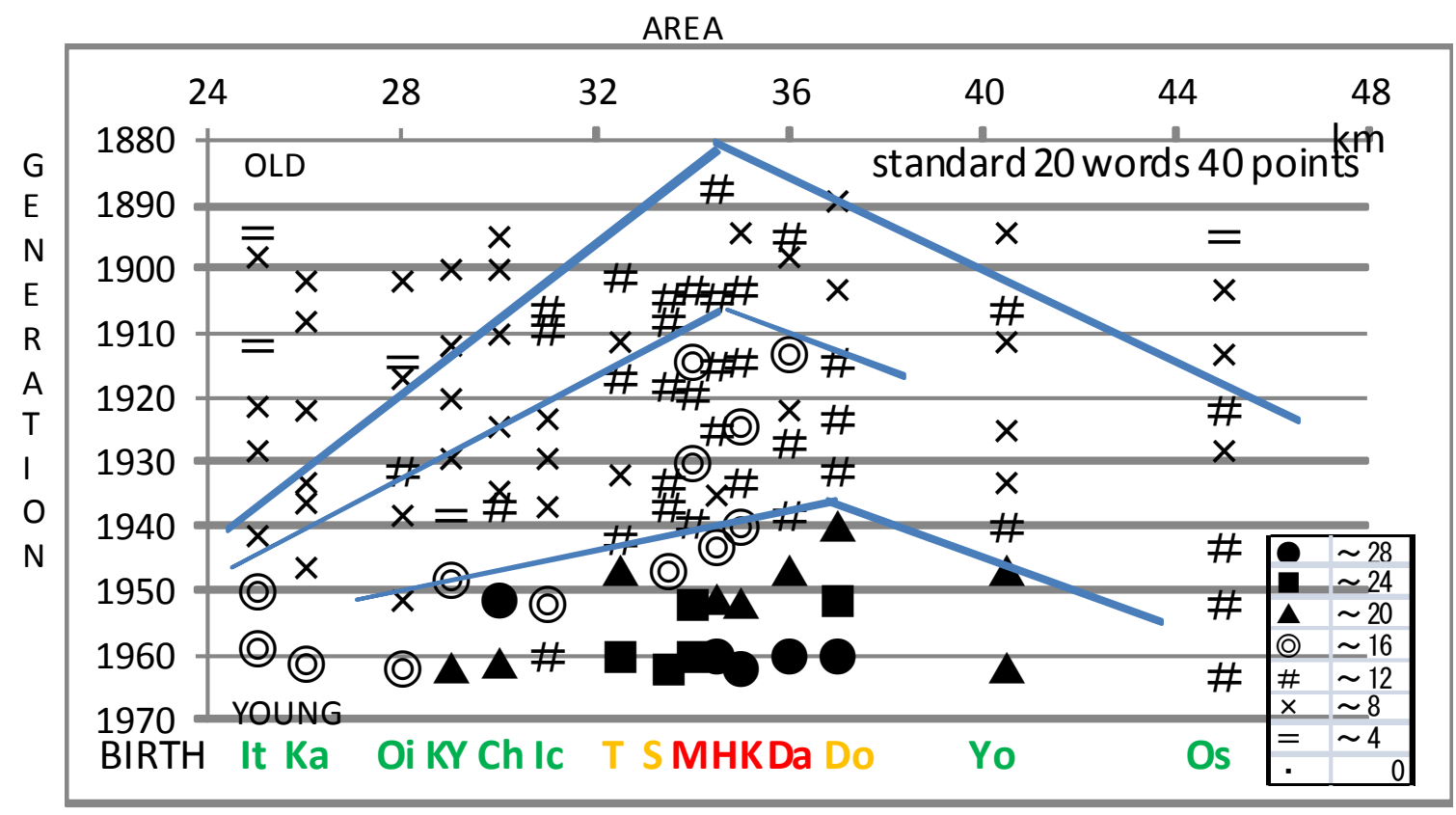

RURAL

SUBURB URBAN SUBURB

RURAL

Figure 4. General distribution patterns of standard Japanese.

\section{Diffusion of New Dialect in glottograms}

\subsection{Definition of "New Dialect"}

Hereafter new dialect forms will be re-analyzed. "New dialect" is defined by three conditions: it is (1) a non-standard linguistic form, (2) used more among younger people, (3) used more in informal situations. In other words, it is a typical linguistic change in progress, and an ongoing change from below (Labov 1994, Inoue 1993, 1999).

The definition of shin-hogen (new dialect) in Japanese dialectology is rather different from that in English dialectology, as treated by Trudgill (1992, 2004). In Japan shin-hogen is used for newly-born forms, and signifies individual linguistic change. On the other hand, English new dialect according to Trudgill is a new linguistic system as a whole, such as colonial language and urban language. 
Dialectologia 17 (2016), 71-89.

ISSN: 2013-2247

\subsection{Shonai Glottogram of New Dialect}

Next, new dialect forms will be presented in the Shonai glottogram. This upper glottogram is the same as Figure 2. In Figure 5, the new dialect form keru, shown by large black squares in Figure 2, will be re-analyzed. As the distances and ages are shown faithfully, the overall distribution pattern looks like a pyramid or mountain centering on the Tsuruoka city area.

Other new dialect forms will be introduced without figures here. Standard Omoshiro katta ('was interesting') is expressed as Omoshe kke by young speakers around Tsuruoka City. However, the distribution is sporadic. Another new dialect form is kaeda, a shortened form of kareda, meaning, 'withered'. This form is used very scarcely. The sporadic use of kaeda among young speakers may be a revival of the old sound change of r-deletion.

When all the data of the 16 new dialect forms were assembled and shown in one glottogram in Figure 6, a pattern which appeared similar to standardization (Figure 4) emerged. That is, the use of new dialect forms is prevalent among young speakers in the city area. However a noticeable difference can be detected. The new dialect forms do not show the simple mountain type distribution. Rather, they show a pattern resembling a steep conide volcano, like Mt Fuji. This means that the new dialect forms born and adopted in the Tsuruoka city area are passed on or handed over to the next generation, but they do not easily diffuse or propagate to the neighboring rural areas. There seems to be a barrier between the city area and rural areas. 


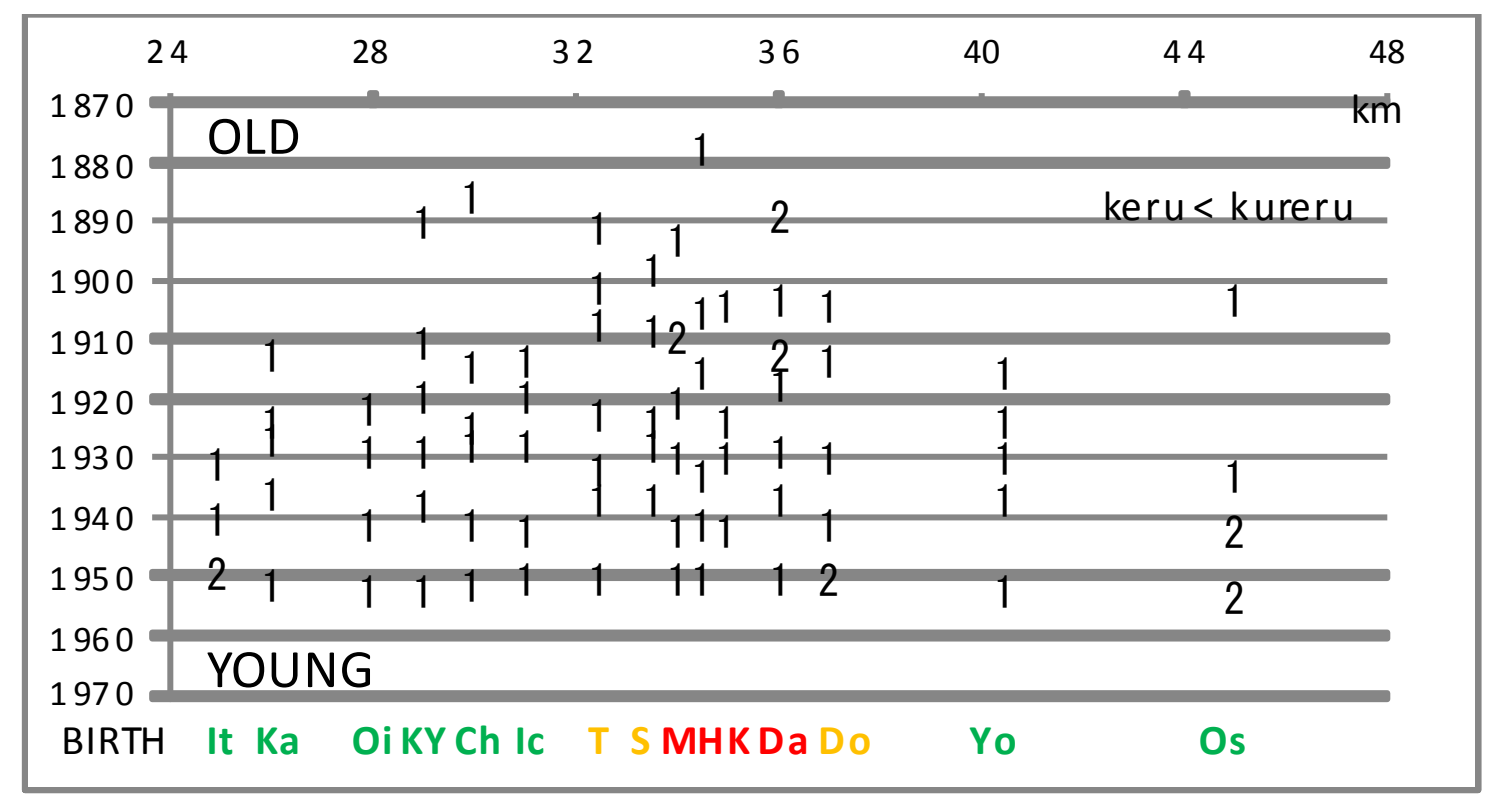

Figure 5. Glottogram of new dialect keru.

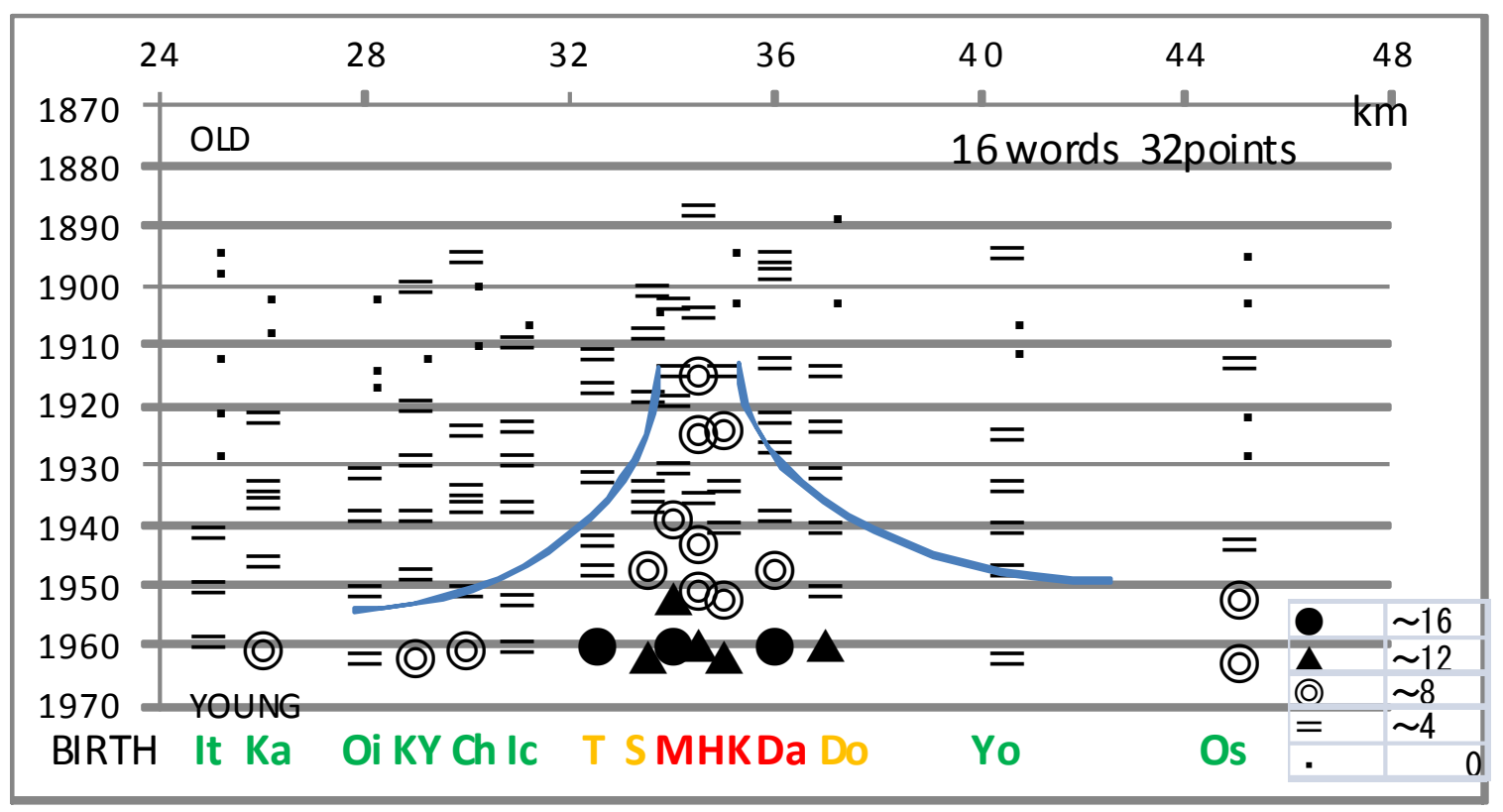

Figure 6. General distribution patterns of new dialect.

\section{Geographical differences of Glottogram data}

In order to grasp the general distribution pattern in the glottograms, for each locality the total usage of standard forms (Figure 4) and of new dialect forms (Figure 6) 
were calculated and shown in Figure 7. Again, geographical distances are shown faithfully. Geographical differences are great as a whole. The informants from the seven ( 4 red and 3 orange) localities of the Tsuruoka city area are by far the heaviest users of standard Japanese and new dialect. The informants from the eight (in green, 6 southern and 2 northern) localities outside the city area do not use standard Japanese or new dialect so much.

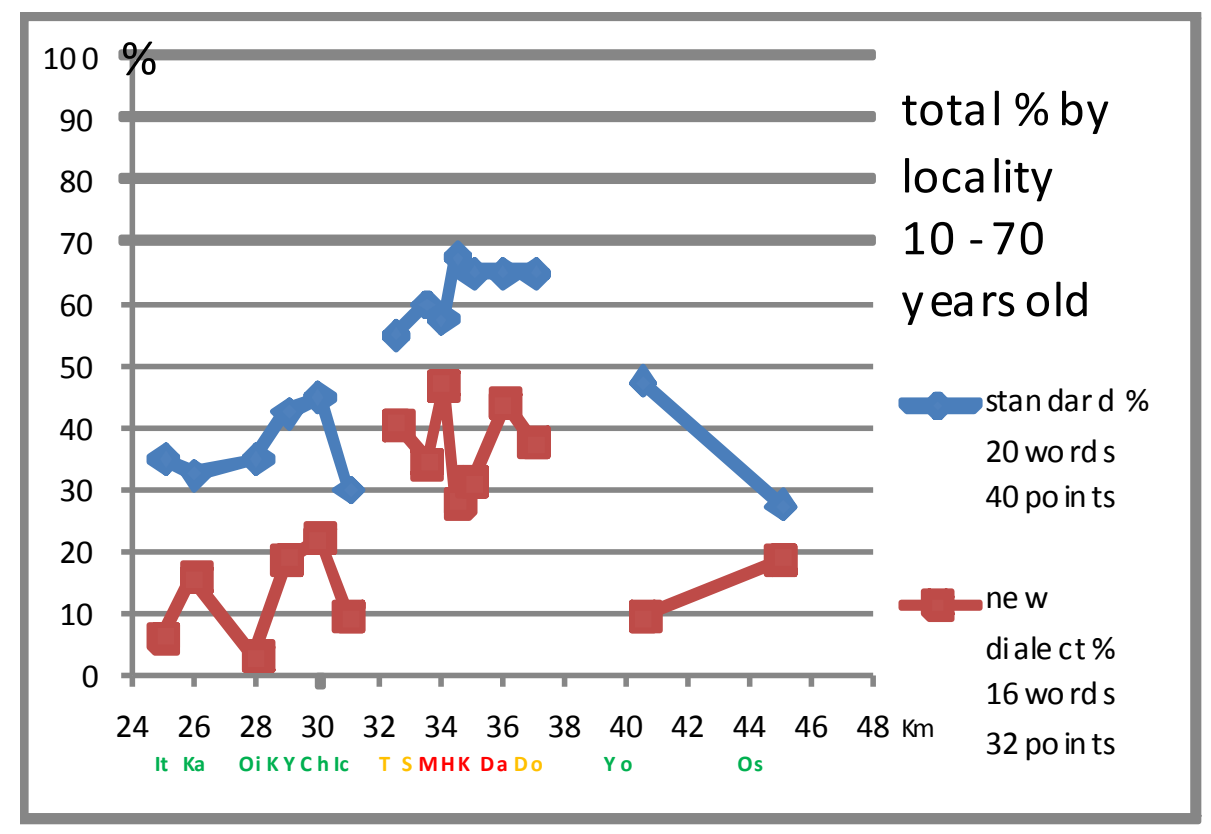

Figure 7. Distribution patterns of standard Japanese and new dialect.

\subsection{Folding at the city center for standard and new dialect}

The glottogram survey is usually executed along a direct line (along a road or along a railway). If we interpret urbanized area to be the center of propagation of new forms, we can metaphorically fold the glottogram in half at the city center, shifting the two peripheral rural areas to a parallel position. Figure 8 is the result of such a procedure. The old samurai area near the Tsuruoka castle (K) was postulated as the cultural city center. In present day, this is a high end residential area where the intellectual and white collar classes live. This location was set as $0 \mathrm{~km}$ and the distances to the other 
locations were recalculated. The eight ( 6 southern and 2 northern) rural localities outside the city area were again plotted faithfully by geographical distance.

The overall tendency was simulated by approximation curves. The blue standard form is most frequently used in the locality $\mathrm{K}$ near the castle. In contrast, red new dialect forms are not used so much in $\mathrm{K}$, while commercial and suburban industrial areas show greater usage. This corresponds with the theory that new dialect is a change from below (typically adopted by young working class people) while standardization is a change from above (typically adopted by young intellectuals).

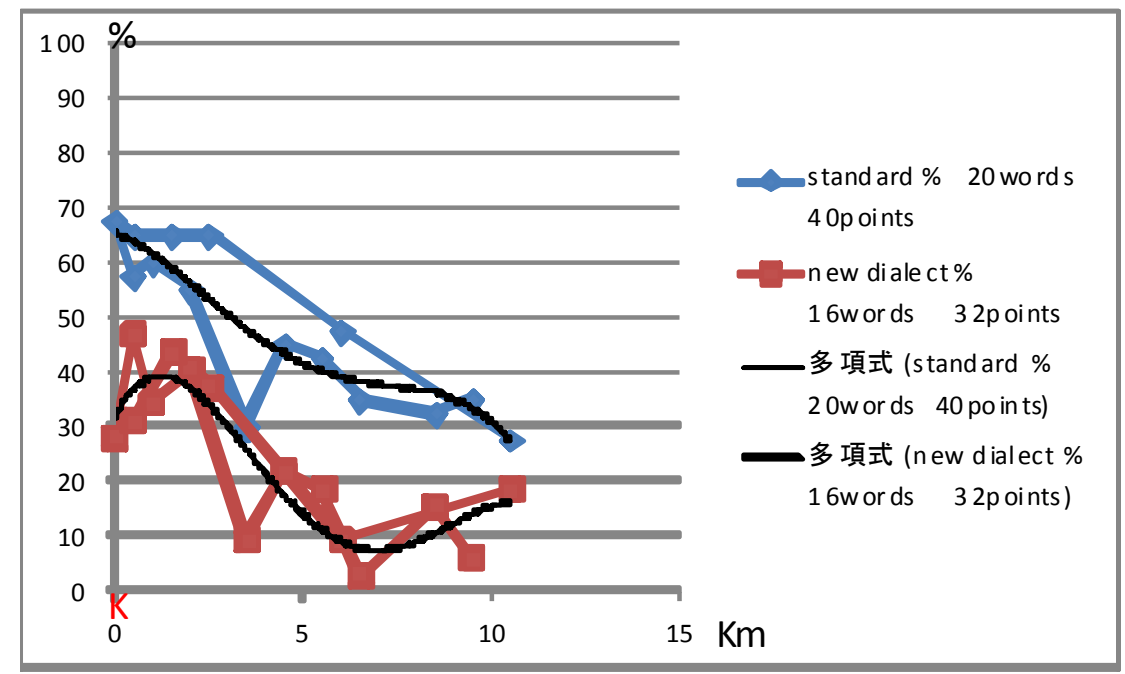

Figure 8. Folding in half at the city center for standard Japanese and new dialect.

\subsection{Area Differences}

In order to further simplify the overall tendency, the seven localities in the Tsuruoka city area are grouped into "urban", and the eight localities outside the city area are grouped into "rural". The differences in Figure 9 are great. The difference in red new dialect is especially marked, at nearly 3 times greater, between 12.9 and 37.5, whereas the difference in blue standard language is less than twice, between 36.5 and 62.1. 


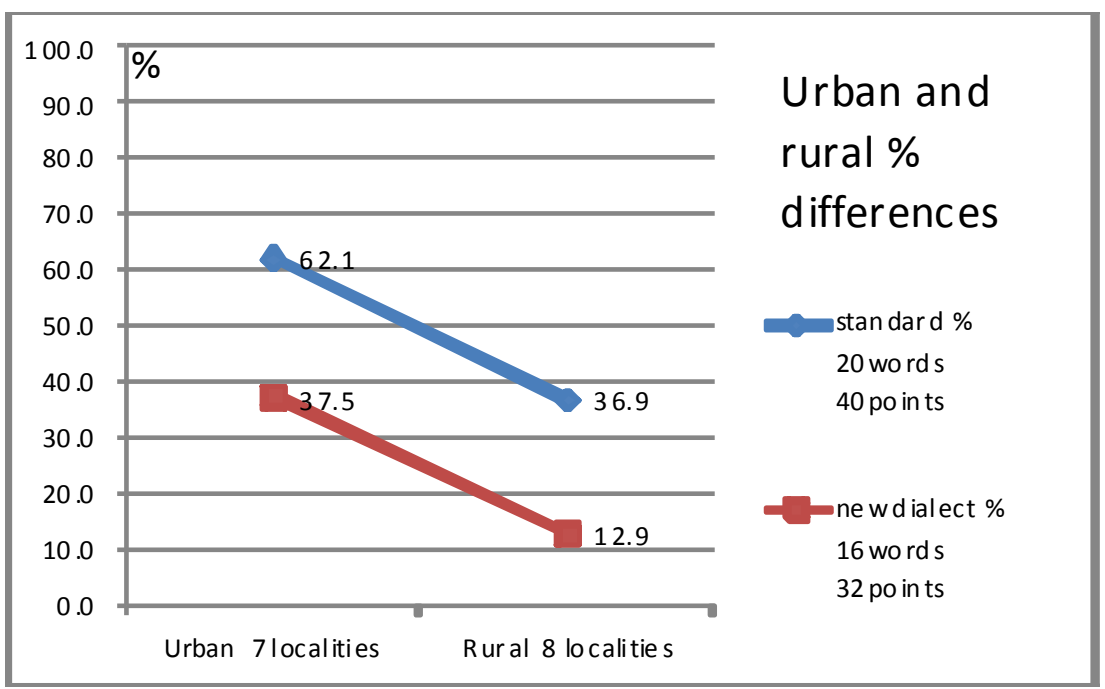

Figure 9. Urban and rural differences.

\subsection{Age Differences}

So far, geographical (or social) differences have been analyzed. In order to grasp the age-based differences in distribution in the glottograms, the sums of usage for standard and new dialect forms were calculated for age groups. The age differences in Figure 10 are conspicuous, especially in the case of standard Japanese. However the age-based differences in new dialect are in a sense far greater, because the relative ratio of older to younger informants is nearly ten times. New dialect forms seem to be regulated by the dimensions of both age and geography.

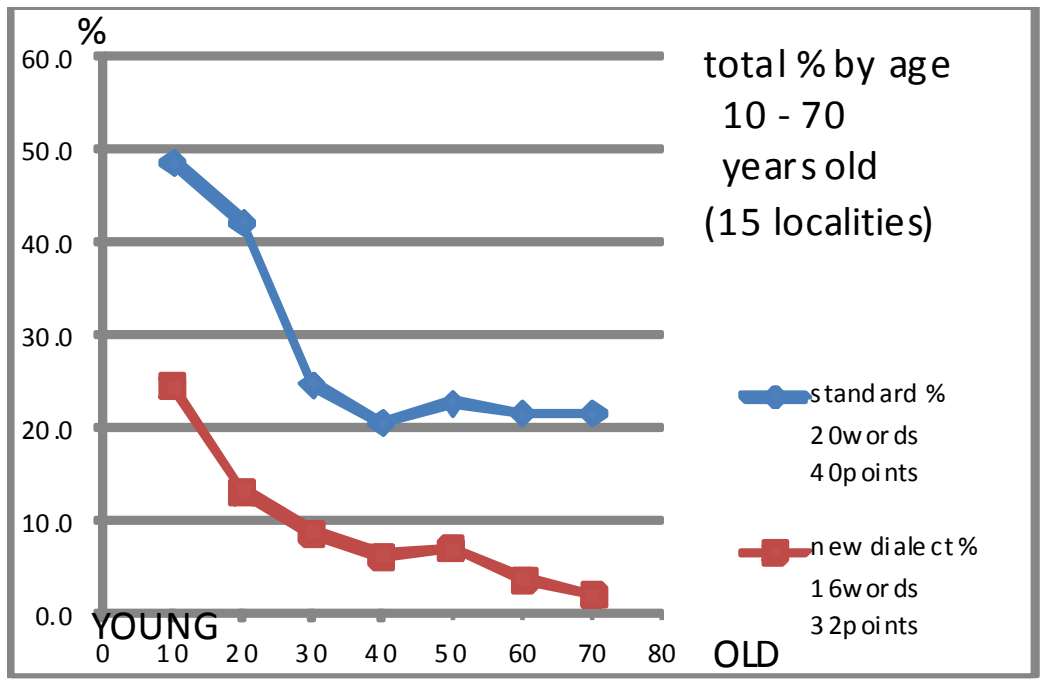

Figure 10. Age-based differences in Glottogram. 


\subsection{Age and Area Differences}

In order to analyze the degrees of age and geographical factors at the same time, informants were further divided into four groups using the two factors. Figure 11 shows that the age factor (left two young and right two old) weighs heavier than the geographical (urban and rural) factor. Age difference is especially great in the case of new dialect forms, with a value difference of "old rural", 0.7, and "young urban", 7.3.

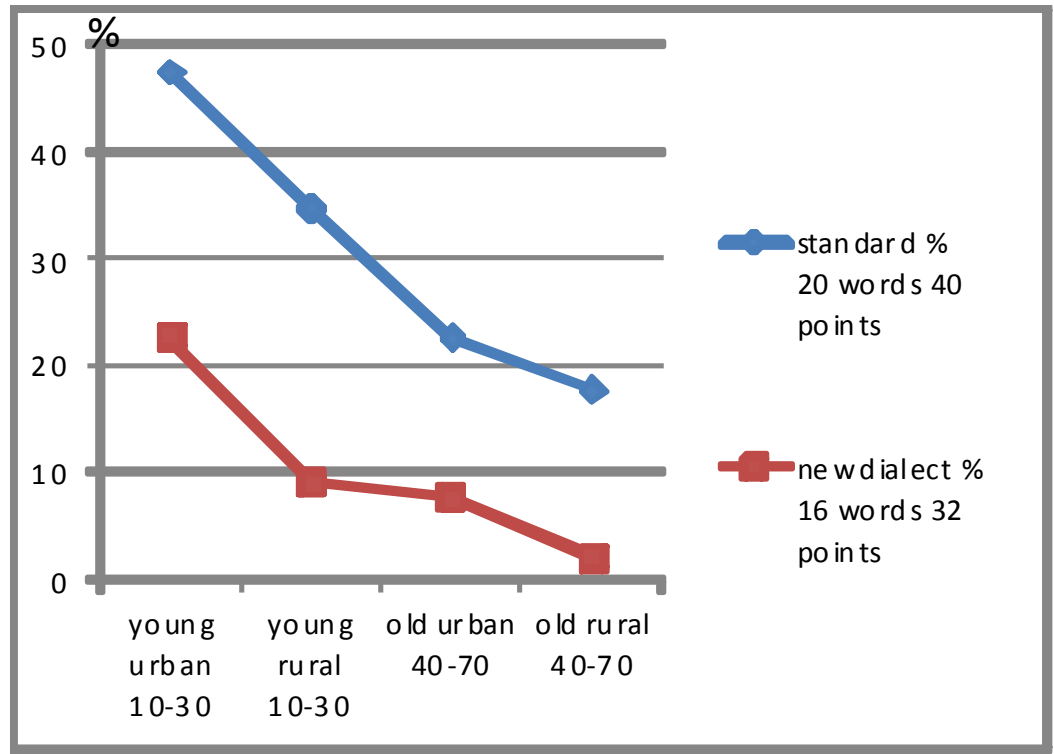

YOUNG OD

Figure 11. Age and area differences in Glottogram.
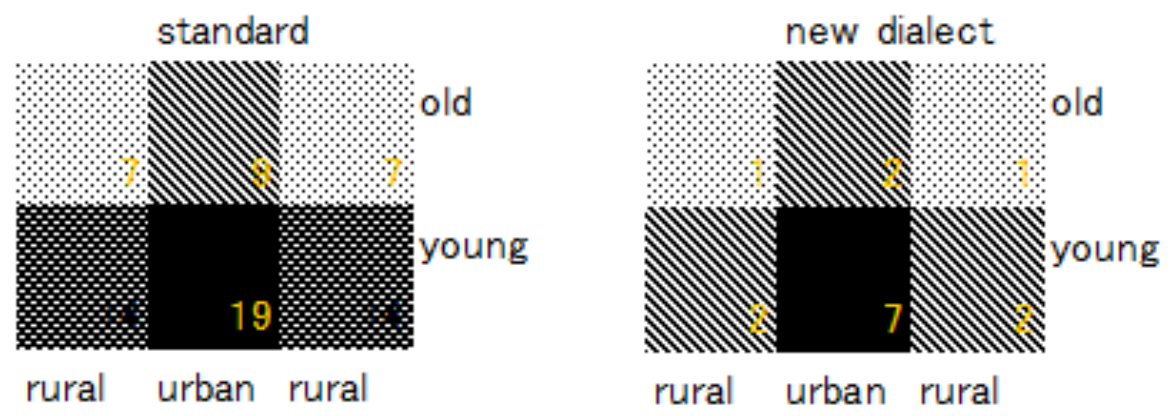

Figure 12. Age and area differences in Glottogram visualized.

The relation above is graphically (or impressionistically) represented in Figure 12 using four (or three) gradients of shade. For standard language (left) the age difference 
is greater, and for new dialect forms (right) the geographical difference is also great. The left-hand figure shows that young rural people use more standard forms than elderly urban people. Meanwhile, the right-hand figure shows that the degree of usage of new dialect is similar for elderly urban people and young rural people, and that the numerical value of urban young people is strikingly great.

\section{Speed of diffusion of standard and new dialect forms}

\subsection{Two patterns of diffusion}

Thus we have seen the differences between two linguistic changes in progress, namely standardization and new dialect. Standard forms can be metaphorically envisioned as soft lava spreading quickly and forming a gently-sloping mountain, like an aspite volcano such as Hawaiian Mauna Kea. New dialect forms can be envisioned as hard lava, spreading slowly and forming a high and steep mountain, like a conide, such as Mt. Fuji.

The distinct patterns of geographical diffusion of standard language and new dialect can be further distinguished using war as a metaphor. Standardization often progresses like paratroopers occupying a small (urban) spot while skipping large (rural) territories. New dialect forms progress slowly and steadily like infantry troops, occupying neighboring (rural) localities one by one.

Standardization is typically a phenomenon of modern times. In contrast, the birth and diffusion of new dialect is a process which has occurred throughout the long history of human language. We can logically surmise that similar processes of diffusion would have occurred even before modern times, and over most of the earth's surface as a universal phenomenon. New dialect is thus a kind of observatory of perennial linguistic changes. 


\subsection{Diffusion speed per year}

On the basis of the findings above, the speed of diffusion of standard Japanese and new dialect forms can be calculated. If we apply linear approximation to the data of Fig 8, diffusion speed per year can be calculated. From the formula, shown in Figure 13, diffusion speed per year is about $0.28 \mathrm{~km} / \mathrm{y}$ for standard language, and $0.33 \mathrm{~km} / \mathrm{y}$ for new dialect.

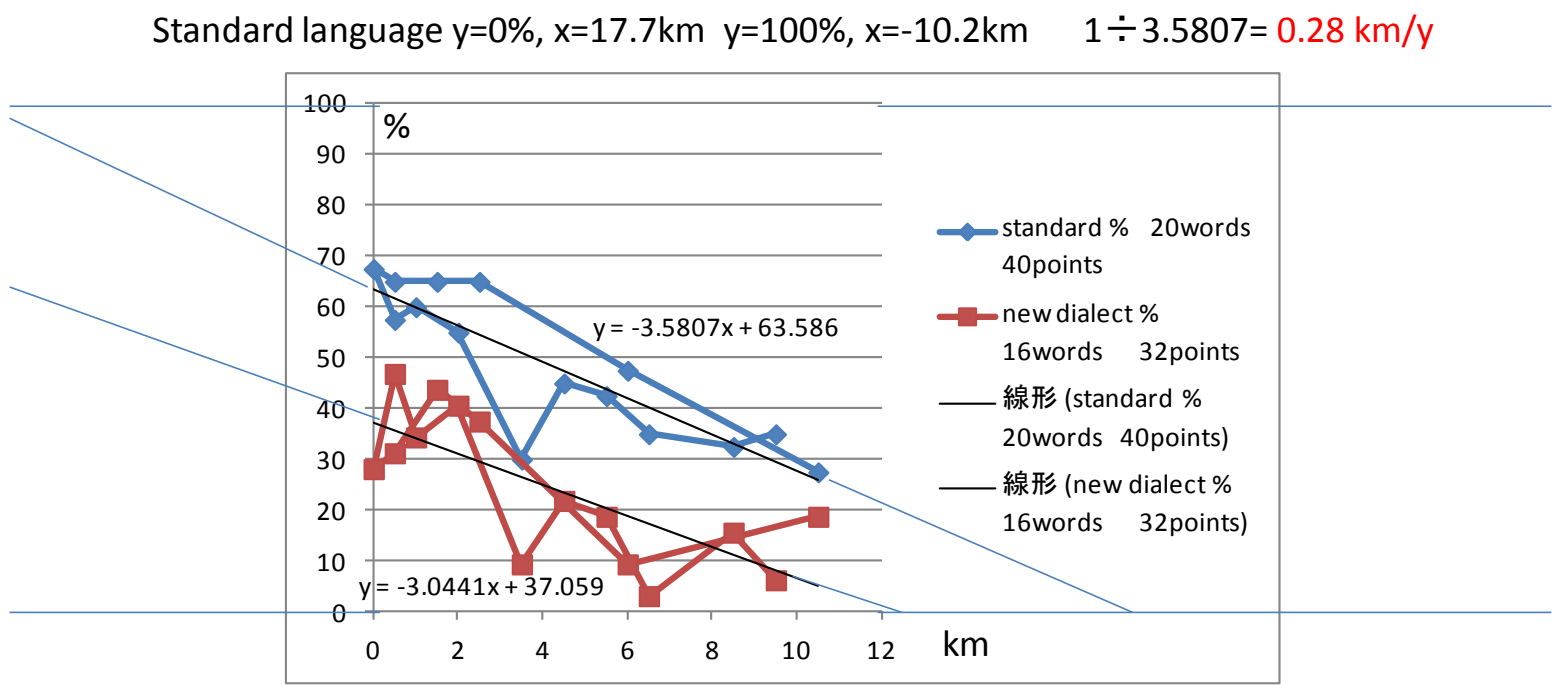

New dialect $y=0 \%, x=12.3 \mathrm{~km} \quad y=100 \%, x=-20.7 \mathrm{~km} \quad 1 \div 3.0441=0.33 \mathrm{~km} / \mathrm{y}$

Figure 13. Diffusion speed on the basis of folded Glottogram.

Speed of dialect diffusion had already been calculated by Tokugawa (1993) for western dialectal forms of LAJ (Linguistic Atlas of Japan). Later I tried to retest the hypothesis using standard Japanese data (Inoue 2010) for 82 standard Japanese forms of LAJ. Multivariate analyses have been applied and West \& East, Classical \& Modern clusters were found (Inoue 2004). I also gathered glottogram data of new dialects all over Japan (Inoue 2003). In order to provide a simple figure to remember, the speed was advocated as about $1 \mathrm{~km}$ per year. More attempts were made recently and it was found there are more varieties and possibilities. Kumagai (2013) is related to this attempt. However, speed of diffusion has not been calculated for the Kumagai data (LAJ) or the Yarimizu (2011) data of GAJ (Grammar Atlas of Japanese Dialects). 
The variety of diffusion speed is shown in the map of Japan which was presented in Canada (Inoue 2010). Speed is shown by like a car speedometer with various angles. The speed is greater on the Pacific Ocean side, which is more densely inhabited and economically developed. It is slower on the Japan Sea side, which is sparsely inhabited and economically less-developed.

Thus far I have exaggerated differences between new dialect and standardization. There is a basic similarity between new dialect and standardization: they peak in young urban people. It is nothing new and is almost universal. Then it is reasonable to formulate this phenomenon in some quantitative way. The speeds of diffusion of standard and new dialect forms around Tsuruoka city can be calculated by making use of the volcano pattern seen in the glottograms earlier. Using age differences and locality distances, as shown in Figure 13, the average speed of diffusion was found to be around $0.3 \mathrm{~km} / \mathrm{y}$, which is slow compared to the nationwide information above. The numerical values of diffusion speed found in Shonai glottogram are low, perhaps because it represents a compact area in the Japan Seaside. This can also be explained by the somewhat scarce communication between the inhabitants of the Tsuruoka city area and the inhabitants of the rural area. The differences can be represented on a map using contour lines. High mountains and large rivers have been pointed out as obstacles to communication and propagation. These are natural obstacles. The social boundaries between urban and rural areas should be admitted as obstacles too. These hindrances to communication can be represented graphically by hypothetical contour lines as shown in Figure 1. This is the basic proposal of this paper.

\subsection{Geographical and Social distances}

The relation between social class and language can be represented in a graph. Urban and rural differences are basically a social distinction which still reflects the distinction from the feudal era (before Meiji Restoration in 1868). Social class differences are also reflected in expected linguistic competence, especially in the use of dialect and standard, and also in the use of honorific language, written language, and English language. 
In order to calculate the diffusion speed of linguistic forms it is advisable to take into account the social dimension. The physical distance between the city area and rural areas is short, but if the social distance is taken into account, the communication distance is large. Hypothetical contour lines can be drawn around a city area to represent this social distance. The attempt to find differences between the Tsuruoka city area and the suburbs so far has shown that the differences amount to approximately one generation's gap (Inoue 2010), which is in congruence with the results of this re-analysis of the glottogram data.

\section{Double Umbrella Model}

\subsection{Umbrella Model}

An umbrella model was once constructed (Inoue 1993, 1999, 2008) to explain the mechanism of linguistic changes from below and from above based on the standard and new dialect forms. Standardization works as a pressure from above to all the areas of Japan. New dialect forms are created and adopted independently in many places in Japan. At the colloquial level, daily speech in Tokyo has the same status as other local dialects. Situated at the rim of an umbrella, Tokyoites and local people exchange new dialectal words and expressions.

The above discussions have shown that local cities like Tsuruoka have their own prestige or power of diffusion. This suggests that small umbrellas should be added on various places as is shown with small umbrellas by this revised graph in Figure 14. This can be called a "double umbrella model". 


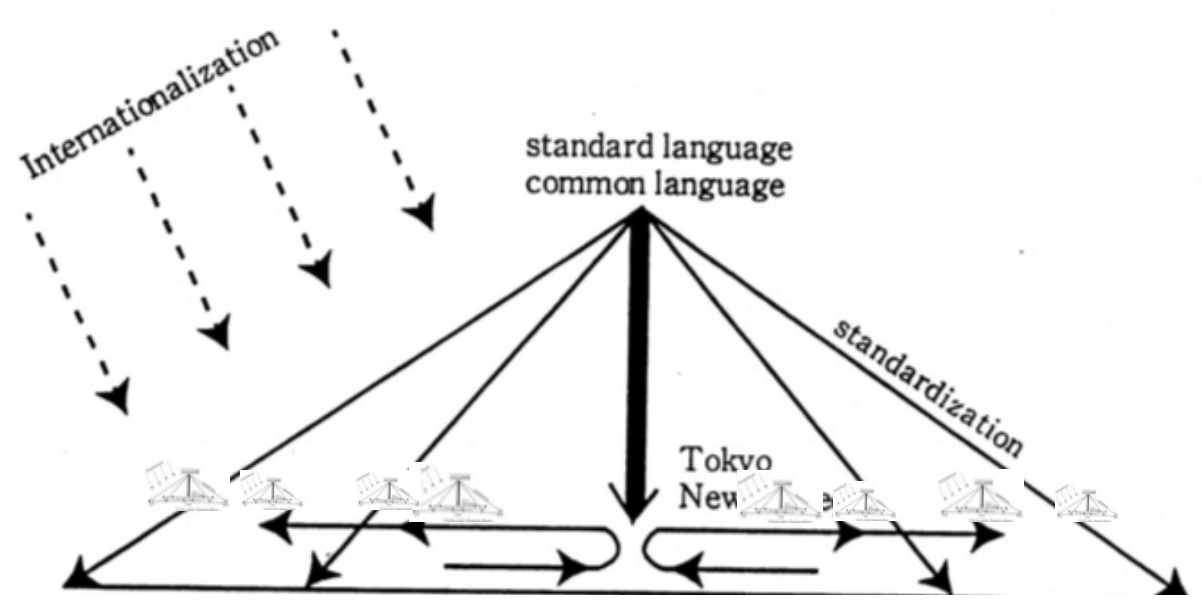

Figure 14. Double umbrella model.

\subsection{Geographical and Social dialects}

Thus far in dialectology NORM or "Non-mobile Older Rural Male" has been the main target of the study (Chambers \& Trudgill 1980). Sociolinguistic studies of urban areas have undergone development since the latter half of the 20th century, and are mainly concerned with the various socioeconomic strata. As the other contrastive extreme of NORM, study of MYUF or "Mobile Young Urban Female" may be crucial in order to properly explain the patterns of linguistic change of standardization and new dialect. The comparison of the inner structure of local cities and their surrounding rural areas, as discussed in this paper, is one step toward the unification of the two main research fields of linguistic geography and sociolinguistics.

In conclusion, we can call the phenomena discussed above, "rural lag". This is a mirror image of "urban prestige". This is a commonsense of dialectologists and sociolinguists. By putting this usual, common process as a basic principle, the exceptional behavior of some new dialect forms which were created in rural areas and diffuse to urban areas will become more prominent. A number of concrete examples of reverse (backward) trends of some "Tokyo new dialect" have been discovered over the past several decades (Inoue 2003, 2010). However, in order to actually measure social and geographical differences, this phenomenon must be studied more formally. These 
class differences between urban and rural inhabitants can be represented by mountains in urban areas using contours on the map as was shown in Figure 1.

\section{Conclusions}

To conclude, a double umbrella model was advocated in this paper. Local cities can be represented as small mountains on a map. They have their own power of propagation and a certain amount of labor is necessary to enter and clime inside. The labor can be represented on a map with contour lines. Rural lag should be taken into account to calculate the speed of diffusion. The speed of diffusion can be calculated more realistically if we take account of the labor of approaching the top of this urban mountain. This way of reasoning will lead to a (happy and) fruitful unification of dialectology and sociolinguistics.

\section{References}

ChAmBers, J. K. \& P. Trudgill (1980) Dialectology, Cambridge: Cambridge University Press. INOUE, Fumio* (1975) "Chiriteki denpa no chosa kibo" (The scale of linguistic geographical surveys)", Kokugogaku, 101,17-28. (Accessible on the internet.)

INOUE, Fumio (1993) "The significance of new dialects" Dialectologia et Geolinguistica, 1, 3-27.

INOUE, Fumio (1999) "Trends of linguistic variations in modern Japan", Area and Culture Studies, 58, 39-46. <http://dictionary.sanseido-publ.co.jp/affil/person/inoue_fumio/doc/E28.pdf>. INOUE, Fumio (2003) Nihongo wa Nensoku 1 kiro de Ugoku (The Japanese Language Moves at 1 km per year), Tokyo: Kodansha Gendai Shinsho.

INOUE, Fumio (2004) "Multivariate analysis, geographical gravity centers and the history of the standard Japanese forms", Area and Culture Studies, 68, 15-36. (Accessible on the internet.)

INOUE, Fumio (2008) "Geographical distance center and multivariate analysis of the standard Japanese", Digalectolologig, 1, 65-81.

$<$ http://www.publicacions.ub.es/revistes/dialectologia1/>. 
Dialectologia 17 (2016), 71-89.

ISSN: 2013-2247

INOUE, Fumio (2010) "Real and apparent time clues to the speed of dialect diffusion", Diglecttologig, 5, 45-64. <http://www.publicacions.ub.edu/revistes/dialectologia5/>.

KUMAGAI, Yasuo (2013) "Development of a way to visualize and observe linguistic similarities on a linguistic atlas", <http://pj.ninjal.ac.jp/socioling/nwavap02/Kumagai-NWAVAP22013.pdf>.

LABOV, William (1972) Sociolinguistic Patterns, Philadelphia: University of Pennsylvania Press.

LABOV, William (1994) Principles of Linguistic Change. Internal Factors, vol. 1, Oxford: Blackwell.

TokUgawa, Munemasa (1993) Hogen chirigaku no tenkai [Development of dialect geography], Tokyo: Hituzi Syobo.

TRUDGILL, Peter (1992) Introducing language and society, London: Penguin Books.

TRUDGILL, Peter (2004) New-Dialect Formation: The Inevitability of Colonial Englishes, Edinburgh: Edinburgh University Press.

YARIMIZU, Kanetaka (2011) "Language Change from the Viewpoint of Distribution Patterns of Standard Japanese Forms", Yuji Kawaguchi, Makoto Minegishi \& Wolfgang Viereck (eds.), Corpus-based Analysis and Diachronic Linguistics, Amsterdam: John Benjamins, 265-284.

* Most of the English papers by $\mathrm{F}$. Inoue are accessible through the internet.

http://innowayf.net/

http://dictionary.sanseido-publ.co.jp/affil/person/inoue_fumio/doc/

http://www.urayasu.meikai.ac.jp/japanese/meikainihongo/18ex/achievements.xls 